\title{
Prevalence of EPIYA Motifs in Helicobacter pylori Strains Isolated from Patients with Dyspeptic Disorders in Northern Iran
}

\author{
Abolghasem Ajami ${ }^{1 *}$, Mojtaba Shadman ${ }^{2}$, Alireza Rafiei ${ }^{1}$, Vahid Hosseini ${ }^{3}$, Amin Talebi-BezminAbadi ${ }^{1}$, Ahad Alizadeh ${ }^{4}$, Zahra \\ Hosseini-khah ${ }^{1}$ \\ ${ }^{1}$ Molecular and cell biology cente, Faculty of medicine, Mazandaran University of Medical Sciences, Sari, Iran. \\ ${ }^{2}$ Department of Immunology, Faculty of Medicine, Mazandaran University of Medical Sciences, Sari, Iran. \\ ${ }^{3}$ Department of Internal Medicine, Imam Hospital, Faculty of Medicine, Mazandaran University of Medical Sciences, Sari, Iran. \\ ${ }^{4}$ Department of Biostatistics, Faculty of Health, Tehran University of Medical Sciences, Tehran, Iran.
}

Received: 25 Aug 2012

Revised: 17 Nov 2012

Accepted: 15 Feb 2013

Corresponding Author Abolghasem Ajami

Department of Immunology, Faculty

of Medicine, Mazandaran University

of Medical Sciences, KM 17

Khazarabad Road, Sari, Iran

Phone: +98-113543614

Email: a.ajami@mazums.ac.ir

\begin{abstract}
Background: Cytotoxin-associated gene A ( $\mathrm{Cag} A)$-positive strains of Helicobacter pylori are associated with gastroduodenal diseases. Evidences have suggested that the type of $H$. pylori CagA EPIYA motifs may be associated with recurrent dyspepsia (i.e. gastritis, peptic ulcer, or gastric cancer). We investigated the prevalence of different EPIYA motifs (A, B, C, or D) in H. pylori strains isolated from patients with recurrent dyspepsia who underwent upper gastrointestinal (GI) endoscopy.

We investigated the prevalence of different EPIYA motifs (A, B, C, or D) in $\mathrm{H}$. pylori strains isolated from patients with recurrent dyspepsia who underwent upper gastrointestinal (GI) endoscopy.

Materials and Method: $H$. pylori strains were isolated from biopsy specimens of 220 patients with recurrent dyspepsia. The presence of $g \operatorname{lm} \mathrm{M}$ gene, as a housekeeping gene, $\operatorname{CagA}$ gene, and pattern of $C a g$ A EPIYA motifs were determined using polymerase chain reaction (PCR) method. The association between the type of motifs and disease state was determined by the Chi-square test, Fisher's exact test, and logistic regression.

Results: $\mathrm{CagA}$-positive $\mathrm{H}$. pylori strains were identified in $125(57 \%)$ of patients, including 36 (28.6\%) gastritis, 31 (24.6\%) duodenal ulcer, and 58 (46.4\%) gastric cancer. The frequency of pattern of CagA EPIYA motifs were detected as 39 (31.2\%) AB motifs, 54 (43.2\%) ABC motifs, 32 (25.6\%) ABCC motifs, and no D motifs. The risk of gastric cancer occurrence was estimated to be 2.57 times higher in patients infected by strains with $\mathrm{ABCC}$ motif when compared with gastritis and duodenal ulcer patients $(p=0.03)$. Moreover, patients with $\mathrm{C}$-containing motifs were 2.27 times more likely to be afflicted with gastric cancer than with duodenal ulcer. $\mathrm{AB}$ motif was more associated with gastritis and duodenal ulcer than $\mathrm{ABC}$ and $\mathrm{ABCC}$ motifs.

Conclusion: The results suggested that CagA-EPIYA ABCC might be associated with gastric cancer, while EPIYA-AB might be associated with duodenal ulcer.
\end{abstract}

Keywords: Helicobacter pylori; Cytotoxin-associated gene A; Dyspeptic disorders

Please cite this article as: Ajami A, Shadman M, Rafiei A, Hosseini V, Talebi-BezminAbadi A, Alizadeh A, Hosseini-khah Z. Prevalence of EPIYA Motifs in Helicobacter pylori Strains Isolated from Patients with Dyspeptic Disorders in Northern Iran. Res Mol Med. 2013; 1 (1): 29-34

\section{Introduction}

Helicobacter pylori colonize in the stomach of more than $50 \%$ of the world's population and play an essential role in the development of various gastroduodenal diseases (such as gastritis, peptic ulcer, and gastric cancer) (1-3). Several potential virulence factors such as $\operatorname{CagA}$, VacA, OipA, and HomB have been suggested to play a role in the pathogenesis of organism (4-5). CagA gene is one of the members of 
a cluster of genes referred to as Pathogenicity Island (PAI) (6). Epidemiological studies have revealed that CagA-positive strains of $H$. pylori are much more likely to be associated with the development of gastric cancer (7-8). CagA-positive strains produce a type IV secretion apparatus that is used to directly inject $C a g A$ into host gastric epithelial cells (9). $C a g A$ is phosphorylated by host cell kinases, forms a complex with SHP-2 (Srchomologyregion 2 containing phosphate 2), and alters multiple host signaling pathways. Dysregulation in this pathway is responsible for increased cell proliferation, cell to cell contact, cell migration, elongation of epithelial cell, and increase in epithelial cell turnover which leads to morphologic changes, inflammation, and atrophy of the infected cells $(6,8,10)$.

CagA is a polymorphic gene containing a highly conserved $5^{\prime}$ end and a variable 3 ' end (4). It contains an EPIYA motif, a repeat region classified in four types, A, B, C, and D. Different strains of $H$. pylori have been detected according to the presence of this repeat region (11). EPIYA-C and -D serve as the primary $\mathrm{CagA}$ phosphorylation sites and are required for binding to SHP-2 (12). Twodifferent combinations of these motifs have been found in two distinct geographical locations, Western $\operatorname{CagA}$ and Eastern CagA (13). EPIYA-A and B are conserved in both two combinations (Western and Eastern), while EPIYA-C (up to 3 repeats) is specific for Western combination, and EPIYA-D is specific for Eastern strains (14). Among Western isolates, molecular epidemiological studies have indicated a correlation between an increased number of EPIYA-C motifs and the type of the consequent disease $(9,12,14)$. Indeed, Western strains isolated from gastric cancer samples, frequently show multiple EPIYA-C motifs $(15,16)$. This increase may be due to elevated morphological transformation because of increased CagA phosphorylation and SHP-2 binding. Eastern CagA containing the EPIYA-D motif demonstrates higher affinity for SHP-2 than Western CagA. This leads to greater morphological changes in infected cells (17) as well as higher levels of inflammation and atrophy (18). These findings along with the fact that Eastern strains predominate in countries with the highest rates of gastric cancer, suggest that Eastern CagA may have the potential to induce more severe forms of gastric disease $(19,20)$. In a study in Tehran, the capital of Iran, CagA motifs isolated from gastric biopsy specimens were demonstrated to be of Western type (21). Since gastric cancer is highly prevalent in northern parts of Iran similar to that of eastern Asia,weproposed that $\mathrm{CagA}$ motif in $H$. pylori isolated from patients in northern Iran might be different from other parts of Iran. Therefore, we investigated the prevalence of different EPIYA motifs in $H$. pylori isolates from the gastric biopsy specimens from the north of Iran.

\section{Material and Methods \\ Patients}

Patients with recurrent dyspeptic symptoms who received upper gastrointestinal (GI) endoscopy at Tooba Outpatients Clinic of Mazandaran University of Medical Sciences (MAZUMS), Sari Iran, were enrolled in the study. Three gastric biopsy specimens were obtained fromeach patient and used for the rapid urease test, $H$. pylori culture, and pathological examinations. All procedures were performed between January 2010 and July 2011. Patients with a history of previous gastric surgery, those who had received $H$. pylori eradication treatment, or those who had recently used $\mathrm{H} 2$ receptor blockers, proton pump inhibitors, and non-steroidal anti-inflammatory drugs (NSAIDs) were excluded. Based on the endoscopic and histopathological assessments, samples were divided into three groups of gastritis, duodenal ulcer, and gastric cancer.The Medical Research Ethic Committee of Mazandaran University of Medical Sciences approved the study protocol and written informed consentsweretakenfromall patients.

\section{Culture of H. pylori}

Biopsy specimens were placed in sterile thioglycolate broth media (Merck, Germany) and quickly transferred to the microbiology lab at $4{ }^{\circ} \mathrm{C}$ for further processing. After dissection and homogenization of the specimens, $100 \mu \mathrm{l}$ of each homogenized specimen was plated on Columbia agar (Mast, UK) containing $7 \%$ fetal calf serum (Gibco, USA), 10\% defibrinated sheep blood (Jihad Daneshgahi, Iran), and H. pylori selective antibiotic tablets (Mast, UK). Plates were incubated at $37{ }^{\circ} \mathrm{C}$ under microaerophilic conditions for 7 days and subcultured from single colonies $H$. pylori colonies were confirmed via morphology, Gram staining, and positive oxidase, catalase, and urease tests. The presence of $H$. pylori colonies was further confirmed by PCR amplified of glmM housekeeping gene, as previously reported (22).

\section{Amplification of the CagA gene}

Genomic DNA was extracted from a single bacterial colony using a commercial kit (Bioneer, South Korea) based on manufacturer's instructions. The presence of $\mathrm{CagA}$ in isolated bacteria was detected bya 298-bp amplicon size as the gene was amplified with primers D008 5'-ATAATCGTAAATTAGACA ACTTGAGCGA-3'and R008 5'-TT AGAATAATCA ACAAACATCACGCCAT-3' using the conditions described previously (5).

\section{Amplification of EPIYA motifs}


For the PCR amplification of the 3' variable region of the $C a g A$ gene containing different EPIYA motifs, we used the two primers designed by Effrosini et al. for EPIYA-A, -B, and -C (23) and the two primers designed by Kathleen et al. for EPIYA-D (3). PCR was performed in a volume of $25 \mu \mathrm{l}$ containing $10 \mathrm{X}$ PCR buffer ( $\mathrm{KCl} 50 \mathrm{mM}$, Tris- $\mathrm{HCl} 10 \mathrm{mM}$, and 1.5\% (vol/vol) triton $\mathrm{x}-100), 1.5 \mathrm{mM} \mathrm{MgCl} 2,100 \mu \mathrm{M}$ of each deoxynuclotides triphosphate (dNTP), $1.5 \mu$ of taq DNA polymerase (Fermentase), 10 pmol of each primer, and $100 \mathrm{ng}$ DNA sample. The reaction took place in an Eppendorf thermo cycler (Hamburg, Germany) under the following conditions: a first denaturation step at $94{ }^{\circ} \mathrm{C}$ for 5 minute following by 30 cycle of $93{ }^{\circ} \mathrm{C}$ for 1 minute, $50{ }^{\circ} \mathrm{C}$ for 45 seconds, and $72{ }^{\circ} \mathrm{C}$ for 1 minute, as well as a final extension at $72{ }^{\circ} \mathrm{C}$ for 5 minutes. PCR products were examined by $1.5 \%$ agarose gel electrophoresis.

\section{Statistical analysis}

The association between the type of motifs and disease state was determined by the Chi-square test, Fisher's exact test, and logistic regression. The logistic model goodness of fit was evaluated with the Hosmer-Lemeshow test. Also association among the mean age with type of motifs, sex and disease states were done by t-test and Univariate Analysis of Variance (ANOVA). Gamma correlation was employed to detect association between two ordinal variables.

\section{Results}

According to microbial culture, $H$. pylori was isolated from 220 biopsy specimens from patients with recurrent dyspeptic symptoms and confirmed by biochemical tests and the presence of $\operatorname{glm} M$ housekeeping gene. PCR amplification of $\mathrm{CagA}$ gene revealed 125 (56.81\%) CagA-positive and $95 \mathrm{CagA}$ negative isolates. Of $125 \mathrm{CagA}$-positive $\mathrm{H}$. pylori isolates, $36(28.6 \%)$ were from patients gastritis, 31 (24.8\%) from duodenal ulcers, and 58 (46.4\%) from gastric cancer (Table 1). The number of detected strains with $\mathrm{AB}$ motif was 39 (31.2\%), with $\mathrm{ABC}$ motifs were $54(43.2 \%)$, and with ABCC motifs were 32 (25.5\%). No EPIYA-D motif was detected. Logistic regression analysis after adjusting the age and sex, demonstrated that cancer risk was estimated to be 2.57 times higher in patients infected by strains with ABCC motif when compared with gastritis and duodenal ulcer patients $(p=0.03)$. For duodenal ulcer and gastritis, there was a reverse correlation between the ABCC motif and both diseases (Table 3) which confirmed that $\mathrm{AB}$ motif was more associated with gastritis and duodenal ulcer than C-containing motifs. Further analyses with Gamma correlation revealed that fewer number of $\mathrm{C}$ motif ( $\mathrm{AB}$ or $\mathrm{ABC}$ ) was correlated with gastritis and duodenal ulcer, while higher number of $\mathrm{C}$ motif was correlated with gastric cancer $(p=0.068)$. Table 2 presents the frequency of $\operatorname{CagA}$ genotypes (EPIYA motifs) in patients with different dyspeptic disorder. EPIYA motifs which contained $\mathrm{C}$ segment (i.e., $\mathrm{ABC}$ and $\mathrm{ABCC}$ motifs) were showed that patients with these motifs were 2.27 times more likely to be afflicted with gastric cancer than duodenal ulcer $(\mathrm{p}=0.068)$. Furthermore, these patients were 1.57 times more likely to be afflicted with gastric cancer than gastritis $(p=0.231)$, and 0.692 times more likely to be afflicted with gastritis than duodenal ulcer $(p=0.318)$.

Table1. Age, sex and disease state of 125 patients that $\mathrm{CagA}$ positive H.pylori isolated.

\begin{tabular}{|c|c|c|c|c|c|c|c|c|}
\hline \multirow[b]{2}{*}{ Sex } & \multicolumn{2}{|c|}{ Gastritis } & \multicolumn{2}{|c|}{ Duodenal ulcer } & \multicolumn{2}{|c|}{ Gastric cancer } & \multicolumn{2}{|c|}{ Total } \\
\hline & $\mathbf{N}(\%)$ & $\begin{array}{c}\text { Age } \\
(\mathrm{mean} \pm \mathrm{SD})\end{array}$ & $\mathbf{N}(\%)$ & $\begin{array}{c}\text { Age } \\
(\mathrm{mean} \pm \mathrm{SD})\end{array}$ & $\mathbf{N}(\%)$ & $\begin{array}{c}\text { Age } \\
(\mathrm{mean} \pm \mathrm{SD})\end{array}$ & $\mathrm{N}(\%)$ & $\begin{array}{c}\text { Age } \\
(\text { mean } \pm \text { SD })\end{array}$ \\
\hline Male & $16(44.4 \%)$ & $49.50 \pm 14$ & $\begin{array}{c}12 \\
(38.7 \%)\end{array}$ & $38.75 \pm 16.91$ & $30(51.7 \%)$ & $46.13 \pm 15.7$ & $58(46.4 \%)$ & $45.53 \pm 15.7$ \\
\hline Female & $20(55.6 \%)$ & $43.10 \pm 17.31$ & $\begin{array}{c}19 \\
(61.3 \%)\end{array}$ & $36.26 \pm 14.55$ & $28(48.3 \%)$ & $39.11 \pm 14.50$ & $67(53.6 \%)$ & $39.4 \pm 15.16$ \\
\hline All patients & $36(28.8 \%)$ & $45.94 \pm 16.03$ & $31(24.8 \%)$ & $36.26 \pm 14.55$ & $58(46.4 \%)$ & $42.74 \pm 15.42$ & $125(100 \%)$ & $42.06 \pm 15.7$ \\
\hline
\end{tabular}

According to microbial culture, $H$. pylori was isolated from 220 biopsy specimens from patients with recurrent dyspeptic symptoms and confirmed by biochemical tests and the presence of $\mathrm{glmM}$ housekeeping gene. PCR amplification of $\mathrm{CagA}$ gene revealed 125 (56.81\%) $\mathrm{CagA}$-positive and $95 \mathrm{CagA}$ negative isolates. Of $125 \mathrm{CagA}$-positive $H$. pylori isolates, $36(28.6 \%)$ were from patients gastritis, 31
(24.8\%) from duodenal ulcers, and 58 (46.4\%) from gastric cancer (Table 1). The number of detected strains with $\mathrm{AB}$ motif was 39 (31.2\%), with $\mathrm{ABC}$ motifs were $54(43.2 \%)$, and with ABCC motifs were 32 (25.5\%). No EPIYA-D motif was detected. Logistic regression analysis after adjusting the age and sex, demonstrated that cancer risk was estimated to be 2.57 times higher in patients infected by strains 
with $\mathrm{ABCC}$ motif when compared with gastritis and duodenal ulcer patients $(p=0.03)$. For duodenal ulcer and gastritis, there was a reverse correlation between the ABCC motif and both diseases (Table 3) which confirmed that $\mathrm{AB}$ motif was more associated with gastritis and duodenal ulcer than C-containing motifs. Further analyses with Gamma correlation revealed that fewer number of $\mathrm{C}$ motif ( $\mathrm{AB}$ or $\mathrm{ABC}$ ) was correlated with gastritis and duodenal ulcer, while higher number of $\mathrm{C}$ motif was correlated with gastric cancer $(\mathrm{p}=0.068)$. Table 2 presents the frequency of $\operatorname{CagA}$ genotypes (EPIYA motifs) in patients with different dyspeptic disorder. EPIYA motifs which contained $\mathrm{C}$ segment (i.e., $\mathrm{ABC}$ and $\mathrm{ABCC}$ motifs) were showed that patients with these motifs were 2.27 times more likely to be afflicted with gastric cancer than duodenal ulcer $(\mathrm{p}=0.068)$. Furthermore, these patients were 1.57 times more likely to be afflicted with gastric cancer than gastritis $(\mathrm{p}=0.231)$, and 0.692 times more likely to be afflicted with gastritis than duodenal ulcer $(\mathrm{p}=0.318)$.

Table 2. Frequency of pattern of cag-A EPIYA motifs in $\mathrm{H}$ pylori

\begin{tabular}{|c|c|c|c|}
\hline $\begin{array}{l}\text { Gastritis } \\
(\mathrm{N}=36)\end{array}$ & $\begin{array}{l}\text { Duodenal ulcer } \\
\qquad(\mathbf{N}=\mathbf{3 1})\end{array}$ & $\begin{array}{c}\text { Gastric cancer } \\
\qquad(\mathrm{N}=58)\end{array}$ & $\begin{array}{r}\text { Total } \\
(\mathrm{N}=125)\end{array}$ \\
\hline EPIYA-AB $12(33.3 \%)$ & $13(41.4 \%)$ & $14(24.1 \%)$ & $39(31.2 \%)$ \\
\hline EPIYA-ABC $16(44.4 \%)$ & $15(48.4 \%)$ & $23(39.7 \%)$ & $54(43.2 \%)$ \\
\hline EPIYA-ABCC $8(22.2 \%)$ & $3(9.7 \%)$ & $21(36.2 \%)$ & $32(25.6 \%)$ \\
\hline
\end{tabular}

According to microbial culture, $H$. pylori was isolated from 220 biopsy specimens from patients with recurrent dyspeptic symptoms and confirmed by biochemical tests and the presence of $\mathrm{glmM}$ housekeeping gene. PCR amplification of $\mathrm{CagA}$ gene revealed 125 (56.81\%) CagA-positive and $95 \mathrm{CagA}$ negative isolates. Of $125 \mathrm{CagA}$-positive $H$. pylori isolates, $36(28.6 \%)$ were from patients gastritis, 31 (24.8\%) from duodenal ulcers, and 58 (46.4\%) from gastric cancer (Table 1). The number of detected strains with $\mathrm{AB}$ motif was $39(31.2 \%)$, with $\mathrm{ABC}$ motifs were 54 (43.2\%), and with ABCC motifs were 32 (25.5\%). No EPIYA-D motif was detected. Logistic regression analysis after adjusting the age and sex, demonstrated that cancer risk was estimated to be 2.57 times higher in patients infected by strains with $\mathrm{ABCC}$ motif when compared with gastritis and duodenal ulcer patients $(\mathrm{p}=0.03)$. For duodenal ulcer and gastritis, there was a reverse correlation between the ABCC motif and both diseases (Table 3) which confirmed that $\mathrm{AB}$ motif was more associated with gastritis and duodenal ulcer than C-containing motifs. Further analyses with Gamma correlation revealed that fewer number of $\mathrm{C}$ motif ( $\mathrm{AB}$ or $\mathrm{ABC}$ ) was correlated with gastritis and duodenal ulcer, while higher number of $\mathrm{C}$ motif was correlated with gastric cancer $(\mathrm{p}=0.068)$. Table 2 presents the frequency of CagA genotypes (EPIYA motifs) in patients with different dyspeptic disorder. EPIYA motifs which contained $\mathrm{C}$ segment (i.e., $\mathrm{ABC}$ and $\mathrm{ABCC}$ motifs) were showed that patients with these motifs were 2.27 times more likely to be afflicted with gastric cancer than duodenal ulcer $(p=0.068)$. Furthermore, these patients were 1.57 times more likely to be afflicted with gastric cancer than gastritis $(p=0.231)$, and 0.692 times more likely to be afflicted with gastritis than duodenal ulcer $(p=0.318)$.

Table 3. Association between $H$ pylori- associated diseases and all variables.

\begin{tabular}{llccc}
\hline & EPIYA motif & N $(\%)$ & OR(95\%CI) & P value \\
\hline Gastritis & & & & \\
& EPIYA-ABb & $12(33.3 \%)$ & 1 & 0.18 \\
& EPIYA-ABC & $16(44.4 \%)$ & $0.58(0.27-1.28)$ & 0.10 \\
& EPIYA-ABCC & $8(22.2 \%)$ & $0.46(0.18-1.17)$ & 0.24 \\
\hline Gastric & & & & \\
Cancer & EPIYA-ABb & $14(24.1 \%)$ & 1 & 0.08 \\
& EPIYA-ABC & $23(39.7 \%)$ & $1.01(.48-2.16)$ & 0.98 \\
& EPIYA-ABCC & $21(36.2 \%)$ & $2.5(1.06-6.28)$ & 0.03 \\
\hline Duoden- & & & & \\
al ulcer & EPIYA-ABb & $13(41.9 \%)$ & 1 & 0.09 \\
& EPIYA-ABC & $15(48.4 \%)$ & $0.96(0.41-2.22)$ & 0.91 \\
& EPIYA-ABCC & $3(9.7 \%)$ & $0.24(.07-0.89)$ & 0.03 \\
\hline
\end{tabular}

a. Adjusted for age and gender

\section{Discussion}

This study showed the strain of $H$. pylori isolated from patients in north of Iran is similar to $H$. pylori types isolated from other regions of Iran: the Western type. No strain with EPIYA-D segment (Eastern strain type) was isolated $(21,24)$. Thus, it seems that although the north of Iran is an endemic region for gastric cancer like East Asian countries (Japan, China, and Korea), the H.pylori strains in the north of Iran are different from those countries. Several in vivo and in vitro studies have reported that EastAsian types of $\operatorname{CagA}$ are associated with higher prevalence of gastric cancer compared to that of Western types; however, there is not enough evidence to explain the role of geographical region in clinical outcome of infection with $C a g A$ positive- $H$. pylori strains (4). Our data revealed that $C a g A$-positive H. pylori with ABCC motifs are associated with the risk of gastric cancer as 2.57 times of the risk of $H$. pylori with $\mathrm{AB}$ motifs. Furthermore, duodenal ulcer was associated with CagA-positive $H$. pylori containing $\mathrm{AB}$ motifs. This finding is in agreement with reports of Baso et al. (9) and Batista et al. (14). In contrast, Shokrzadeh et al. found no difference between EPIYA-C types and clinical outcomes in Tehran, Iran (21). This difference may be due to small number of samples in this study (i.e. 11 cases with peptic ulcer disease and 4 cases with gastric cancer in the study by Shokrzadeh et al.). Another possibility is the geographical difference, since north of Iran is a high risk area for developing gastric 
cancer (25). Gamma correlation test revealed that with increasing the numbers of EPIYA-C motifs, the risk of gastric cancer increased as well. There are many reports about the role of EPIYA motifs of CagA in pathogenicity of $H$. pylori. Following injection of $C a g A$ protein into the gastric and duodenal epithelial cells, the EPIYA motifs are tyrosine phosphorylated by $\mathrm{Src}$ and $\mathrm{Ab} 1$ family kinases, which result in the impairment of a variety of intracellular signaling pathways (10). The number of present EPIYA motifs is related to the level of $\mathrm{CagA}$ phosphorylation that occurs in epithelial cells infected by $H$. pylori (4). Patients infected with a H. pylori strain with stronger $C a g A$ phosphorylation have more sever chronic inflammation with an increased risk of gastric cancer. Also it is important to note the due to this fact that tyrosinephosphorylated EPIYA-C makes as many sites to interact $\operatorname{CagA}$ protein with SHP-2 domains of host cells. This binding activates SHP-2 and induction of stronger and longer periods of SHP-2 activity which leads to an increased signal transduction, more morphological damage, and finally the development of gastric cancer. Recent studies indicated the prevalence of strains with more than one repeat region (such as $\mathrm{ABCC}$ ) as $51.1 \%$ in Colombia, $33.3 \%$ in Italy (20), and $3.3 \%(21)$ and $12 \%(24)$ in two different parts of Iran, while the present study showed the prevalence of these strains in the north of Iran as $25.6 \%$. As mentioned before, these differences may be due to the high prevalence of gastric cancer and geographical and environmental difference in northern parts of Iran. Overall, the current study confirmed patients with one or more repeats of the $\mathrm{C}$ region showed a 2.27 -fold increased risk of developing gastric cancer than duodenal ulcer.

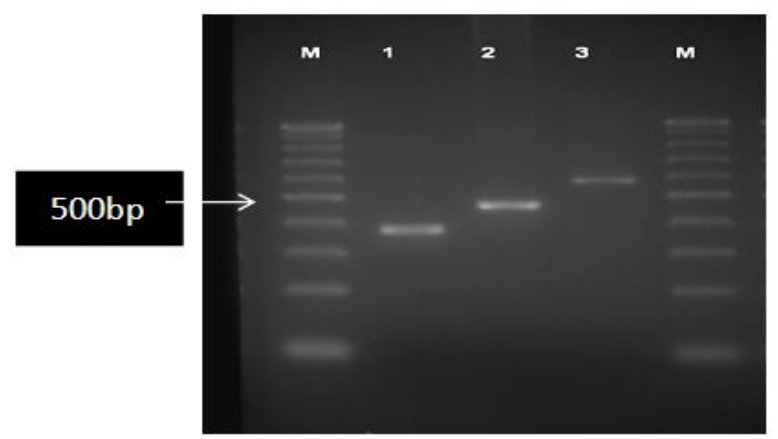

Figure 1. PCR products of the $\operatorname{CagA} 3^{\prime}$ end variable region. $\mathrm{M}=$ DNA marker [100bp- 1000bp]; lane 1: AB motifs (379 bp), lane 2: $\mathrm{ABC}$ motifs (470 bps), and lane 3: ABCC motifs (570 bps).

Also it is important to note the due to this fact that tyrosine-phosphorylated EPIYA-C makes as many sites to interact $\operatorname{CagA}$ with SHP-2 domains of host cells. This binding activates SHP-2 and induction of stronger and longer periods of SHP-2 activity, leads to an increased signal transduction, greater morphological damage, and involved in development of gastric cancer. Therefore recent studies indicated prevalence of strains with more than one repeat region (such as $\mathrm{ABCC}$ ) was $51.1 \%$ in Colombia and $33.3 \%$ in Italy population (20), also this current study $25.6 \%$ but in other recent studies in Iran revealed $3.3 \% \quad(21)$ and $12 \%$ (24). This discordant as mentioned before, may be due to the high prevalence of gastric cancer and geographical and environmental difference in northern parts of Iran. Overall this current study confirmed patients with one or more repeats of the $\mathrm{C}$ region showed a 2.27 -fold increased risk of developing gastric cancer than duodenal ulcer. With regard to this result we proposed to exact understanding the role of EPIYA motif in gastroduodenal diseases in population of Iran, Other studies needed to investigate the role of EPIYA motif in gastroduodenal diseases in other provinces with high incidence of gastric cancer such as Ardabil, golestan and gilan to compare with this recent studies.

\section{Conclusion}

There was a significant statistical association between the presence of the type of CagA EPIYA motifs of $H$. pylori and the development of dyspeptic disorders. EPIYA-CC was significantly associated with gastric cancer, while EPIYA-AB was associated with duodenal ulcer. It should be noted that the presence of an EPIYA-CC does not necessarily lead to a gastric cancer since there was a high percentage of patients with gastritis and duodenal ulcer infected with $H$. pylori containing EPIYA-C or EPIYA-CC motifs. Further studies needed to investigate the role of EPIYA motifs in patients with dyspeptic disorders in other provinces of Iran which are endemic regions of gastric cancer such as Ardabil, Golestan and Gilan provinces.

\section{Acknowledgments}

This work was supported by a grant of the Molecular and Cell Biology Research Center (MCBRC), Mazandaran University of Medical Sciences.

\section{References}

1. Megraud F, Lamouliatte H. Helicobacter pylori and duodenal ulcer. Evidence suggesting causation. Dig Dis Sci. 1992; 37(5):769-72. PMID: 1563322

2. Parsonnet J, Friedman GD, Vandersteen DP, Chang Y, Vogelman JH, Orentreich N, et al. Helicobacter pylori infection and the risk of gastric carcinoma. N Engl J Med. 1991; 325(16):1127-31. PMID: 1891020

3. Jones KR, Joo YM, Jang S, Yoo YJ, Lee HS, Chung IS, et al. Polymorphism in the CagA EPIYA motif impacts development of 
gastric cancer. J Clin Microbiol. 2009; 47(4):959-68. PMID: 19158258

4. Yamaoka Y. Mechanisms of disease: Helicobacter pylori virulence factors. Nat Rev Gastroenterol Hepatol. 2010; 7(11):62941. PMID: 20938460

5. Talebi Bezmin Abadi A, Rafiei A, Ajami A, Hosseini V, Taghvaei T, Jones KR, et al. Helicobacter pylori homB, but not $\mathrm{CagA}$, is associated with gastric cancer in Iran. J Clin Microbiol. 2011; 49(9):3191-7. PMID: 21734027

6. Sicinschi LA, Correa P, Peek RM, Camargo MC, Piazuelo MB, Romero-Gallo J, et al. CagA C-terminal variations in Helicobacter pylori strains from Colombian patients with gastric precancerous lesions. Clin Microbiol Infect. 2010; 16(4):369-78. PMID: 19456839

7. Stein M, Rappuoli R, Covacci A. Tyrosine phosphorylation of the Helicobacter pylori $\mathrm{CagA}$ antigen after cag-driven host cell translocation. Proc Natl Acad Sci U S A. 2000; 97(3):1263-8. PMID: 10655519

8. Zambon CF, Navaglia F, Basso D, Rugge M, Plebani M Helicobacter pylori babA2, CagA, and s1 vacA genes work synergistically in causing intestinal metaplasia. J Clin Pathol. 2003; 56(4):287-91. PMID: 12663641

9. Basso D, Zambon CF, Letley DP, Stranges A, Marchet A, Rhead $\mathrm{JL}$, et al. Clinical relevance of Helicobacter pylori $\mathrm{CagA}$ and vacA gene polymorphisms. Gastroenterology. 2008; 135(1):91-9. PMID: 18474244

10.Higashi H, Yokoyama K, Fujii Y, Ren S, Yuasa H, Saadat I, et al. EPIYA motif is a membrane-targeting signal of Helicobacter pylori virulence factor $\mathrm{CagA}$ in mammalian cells. J Biol Chem. 2005; 280(24):23130-7. PMID: 15831497

11. Zhang Y, Argent RH, Letley DP, Thomas RJ, Atherton JC. Tyrosine phosphorylation of CagA from Chinese Helicobacter pylori isolates in AGS gastric epithelial cells. J Clin Microbiol. 2005; 43(2):786-90. PMID: 15695680

12. Salih BA, Bolek BK, Arikan S. DNA sequence analysis of CagA 3' motifs of Helicobacter pylori strains from patients with peptic ulcer diseases. J Med Microbiol. 2010; 59(Pt 2):144-8. PMID: 19850704

13. Truong BX, Mai VT, Tanaka H, Ly le T, Thong TM, Hai HH, et al. Diverse characteristics of the CagA gene of Helicobacter pylori strains collected from patients from southern vietnam with gastric cancer and peptic ulcer. J Clin Microbiol. 2009; 47(12):4021-8. PMID: 19846630

14. Batista SA, Rocha GA, Rocha AM, Saraiva IE, Cabral MM, Oliveira RC, et al. Higher number of Helicobacter pylori CagA EPIYA C phosphorylation sites increases the risk of gastric cancer, but not duodenal ulcer. BMC Microbiol. 2011; 11(61):1471-2180. PMID: 21435255
15. Dixon MF, Genta RM, Yardley JH, Correa P. Classification and grading of gastritis. The updated Sydney System. International Workshop on the Histopathology of Gastritis, Houston 1994. Am J Surg Pathol. 1996; 20(10):1161-81. PMID: 8827022

16. Satomi S, Yamakawa A, Matsunaga S, Masaki R, Inagaki T, Okuda T, et al. Relationship between the diversity of the CagA gene of Helicobacter pylori and gastric cancer in Okinawa, Japan. J Gastroenterol. 2006; 41(7):668-73. PMID: 1933004

17. Higashi H, Tsutsumi R, Fujita A, Yamazaki S, Asaka M, Azuma $\mathrm{T}$, et al. Biological activity of the Helicobacter pylori virulence factor $\operatorname{CagA}$ is determined by variation in the tyrosine phosphorylation sites. Proc Natl Acad Sci U S A. 2002; 99(22):14428-33. PMID: 12391297

18. Azuma T, Yamazaki S, Yamakawa A, Ohtani M, Muramatsu A, Suto $\mathrm{H}$, et al. Association between diversity in the Src homology 2 domain--containing tyrosine phosphatase binding site of Helicobacter pylori $\mathrm{CagA}$ protein and gastric atrophy and cancer. J Infect Dis. 2004; 189(5):820-7. PMID: 14976598

19. Ahn YO, Park BJ, Yoo KY, Kim NK, Heo DS, Lee JK, et al. Incidence estimation of stomach cancer among Koreans. J Korean Med Sci. 1991;6(1):7-14. PMID: 1888453

20. Yamaoka Y, El-Zimaity HM, Gutierrez O, Figura N, Kim JG, Kodama T, et al. Relationship between the CagA 3' repeat region of Helicobacter pylori, gastric histology, and susceptibility to low pH. Gastroenterology. 1999;117(2):342-9. PMID: 10419915

21. Shokrzadeh L, Baghaei K, Yamaoka Y, Dabiri H, Jafari F, Sahebekhtiari N, et al. Analysis of 3'-end variable region of the CagA gene in Helicobacter pylori isolated from Iranian population. J Gastroenterol Hepatol. 2010; 25(1):172-7. PMID: 19793167

22. Lu JJ, Perng CL, Shyu RY, Chen CH, Lou Q, Chong SK, et al. Comparison of five PCR methods for detection of Helicobacter pylori DNA in gastric tissues. J Clin Microbiol. 1999; 37(3):772-4. PMID: 9986850

23.Panayotopoulou EG, Sgouras DN, Papadakos K, Kalliaropoulos A, Papatheodoridis G, Mentis AF, et al. Strategy to characterize the number and type of repeating EPIYA phosphorylation motifs in the carboxyl terminus of CagA protein in Helicobacter pylori clinical isolates. J Clin Microbiol. 2007; 45(2):488-95. PMID: 17151214

24. Hussein NR, Mohammadi M, Talebkhan Y, Doraghi M, Letley DP, Muhammad MK, et al. Differences in virulence markers between Helicobacter pylori strains from Iraq and those from Iran: potential importance of regional differences in $H$. pylori-associated disease. J Clin Microbiol. 2008; 46(5):1774-9. PMID: 18353934

25. Malekzadeh R, Derakhshan MH, Malekzadeh Z. Gastric cancer in Iran: epidemiology and risk factors. Arch Iran Med. 2009; 12(6):576-83. PMID: 19877751 